\title{
Presencia y contenidos de los blogs de autor en los ciberdiarios del grupo Vocento
}

Koldobika Meso Ayerdi Universidad del País Vasco

\section{Resumen}

A lo largo de 2005, algunos de los ciberdiarios del grupo Vocento fueron los primeros medios en ofrecer blogs en sus sitios de Internet elaborados por periodistas del propio cibermedio o personal cualificado que los emplean para mantener un contacto con su audiencia. Seis años después, el número de títulos se ha multiplicado exponencialmente y han conseguido una mayor visibilidad integrándose en las portadas de estos ciberdiarios. En la presente comunicación analizaremos los «blogs de autor o firmados» de los ciberdiarios del grupo Vocento y cómo han aplicado medidas hasta lograr contar con una sección propia. Sus temáticas son muy variadas, así como su autoría, las actualizaciones de sus contenidos y las posibilidades que ofertan de recibir los comentarios de aquellas personas que los leen, y que expresan su opinión de una forma interactiva, enriqueciendo las ideas manifestadas en los mismos y permitiendo profundizar en ellas. Añaden fotografías, enlaces a otros blogs, ponen a disposición de los usuarios todo el archivo. Y detrás de ello, la intención de crear comunidad.

\section{Palabras claves}

Blogs, Ciberdiarios, Internet, Vocento, Blogs de autor, Interactividad 


\title{
Presence and contents of author blogs in Vocento's cyberdiaries
}

\begin{abstract}
:
During 2005, some of Vocento's cybernewspapers started hosting blogs written by their journalists or qualified guests to keep in touch with the audience. Six years later, the total amount of titles has increased exponentially and have achieved greater visibility by getting integrated in the main page of these cyberdiaries. On this text, we analyze the Vocento's cybernewspapers "author blogs» or "signed blogs» and how they have been incorporated into the digital newspaper to the point where they now have their own section. There is a wide range of topics, authors, updates and the possibilities of receiving comments and interactive ways are very different too. It enriches the ideas published through the posts, drawing a deeper content. They add pictures, blog links and the access to a huge archive with all their posts. Behind this activity, the intention of creating communities.
\end{abstract}

\section{Keywords}

Weblogs, Cybernewspaper, Internet, Vocento, Author Weblogs, Interactivity

\section{Autor}

Koldobika Meso Ayerdi [koldo.meso@ehu.es] es doctor en Ciencias de la Información por la Universidad del País Vasco. Es profesor titular de la Facultad de Ciencias Sociales y de la Comunicación de la misma Universidad, donde imparte las asignaturas de Modelos de los Medios de Comunicación e Introducción al Periodismo. 


\section{Introducción}

Durante los primeros años del tercer milenio, los blogs se han convertido en el principal fenómeno comunicativo de carácter verdaderamente renovador (López y Otero, 2007). En enero de 2005, Fortune situaba a los blogs como la tendencia tecnológica más importante en las áreas de publicidad, marketing y relaciones públicas. Un mes después, The Economist dedicaba un artículo a Robert Scoble, blogger de Microsoft, en el que se sugería que el blogging conduciría a la muerte de las relaciones públicas tradicionales ${ }^{1}$. En diciembre de 2006, la revista Time nombraba «persona del año» a todos los usuarios de la Web 2.0: «Time’s Person of the Year: You».

En esos años del siglo XXI, los medios digitales empezaron a desligarse de sus modelos analógicos y a aprovechar las posibilidades expresivas e interactivas específicas del canal Internet. El blog era, del conjunto de medios digitales, el que más éxito estaba teniendo y el que más estaba experimentando e innovando. Su potencial como medio radicaba en el carácter bidireccional de la comunicación que establece y en la facilidad para formar redes con otros blogs y otros medios (Ortiz de Zárate, 2008).

Y los ciberdiarios se hicieron con él, precisamente cuando comenzaba a dilucidarse que los nuevos escenarios del periodismo estarían estrechamente relacionados con las extensiones tecnológicas habilitadas por Internet (Smith, 2010).

Asistimos a un proceso de cambio en los productos periodísticos, en la profesión periodística y en la relación con la audiencia. Esta transformación no sólo guarda una estrecha relación con el nacimiento de un nuevo canal de transmisión, sino también de una nueva retórica periodística que llega a través de los cibermedios y que tiene en la participación de los usuarios una práctica habitual (Palomo y Meso, 2009). Precisamente, Tapscott y Williams (2007) coinciden en señalar en la capacidad de los cibermedios de incorporar escenarios abiertos a la participación ciudadana para afrontar los retos que se presentaban. Si bien, la principal complejidad en esos escenarios futuros de los cibermedios radicaría en determinar cuáles serían los grados de participación de los usuarios en los medios (Pisani y Piotet, 2009).

Ya en 2003, J.D. Lasica argumentaba en un artículo que los periódicos estaban perdiendo una gran oportunidad de mejorar su relación con los lectores y de aprovechar todo el saber y las oportunidades de sus reporteros, y por eso pedía introducir el blogging en la redacción. «Los diarios están perdiendo una oportunidad por negarse a usar los weblogs, que crean la oportunidad de construir una confianza, una relación de convivencia con los lectores del diario y, a menudo, proporcionan un extra de claves y ángulos sobre la información» (2003).

Los medios comenzaron a ser conscientes del papel que jugaban las comunidades de usuarios y del poder de toda una serie de nuevos servicios: blogs, RSS, foros, wikis, redes sociales, en definitiva, todo un catálogo de 'tecnologías del yo'

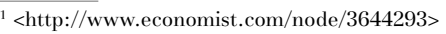


(Orihuela, 2006), en las que la voz de la comunidad pasaba a ser tan importante como la de los tradicionales proveedores de información.

Los diarios digitales comenzaron a disponer de algunas de las herramientas que hacían posible que los ciudadanos pudieran comunicarse con otros ciudadanos, pudieran opinar y difundir sus puntos de vista sobre un tema; o, simplemente, pudieran expresarse. Se inauguraba una nueva época, con oportunidades infinitas, y los blogs habrían de jugar un papel, cuando menos, interesante. Posibilitaban un mayor protagonismo no sólo a los periodistas, sino también al ciudadano y una mayor autonomía para poder desarrollar sus habilidades comunicativas.

Y ello a pesar de existir la creencia de que las motivaciones de desarrollar todos estos nuevos servicios encuadrados en lo que se ha venido a denominar Web 2.0 estaban relacionadas con estrategias de marketing, con la seguridad de que los mecanismos de participación ofrecían la posibilidad de fidelizar audiencias (López, 2008; Ruiz et al, 2009), lo que Carrillo y Castillo (2009: 29) han denominado «fenómeno de moda».

Las consecuencias de la multiplicación de los blogs, con formatos muy diversos y temáticas muy diferentes, han sido enormes. Su presencia ha modificado los hábitos de los usuarios, quienes se interesan por seguir día a día los blogs que les resultan atractivos, $\mathrm{y}$ ha incidido en las propias relaciones entre internautas y entre éstos y el cibermedio que los aloja. Y además, «la sociedad irrumpe en los procesos de producción y reclama su sitio allí donde se negocia el control de los acontecimientos» (García de Torres y Pou Amérigo, 2003: 49). Y es que, el periodismo del futuro debe estar más interconectado y ser más transparente e interactivo (Beckett, 2010).

A medida que pasan los días, cada vez son más los ciudadanos que crean sus propios blogs, pero también son cada vez más los cibermedios que hacen el esfuerzo por fortalecer los mecanismos para que estos ciudadanos puedan alojar en su web blogs que ellos mismos crean, que se nutren de aportaciones que realizan de manera secuencia, que les posibilita hacerse oír y llegar a miles de personas sus comentarios políticos, o lo que opinan sobre la marcha de su equipo favorito, o hablarles de sus aficiones y encontrar a otras personas que las comparten. Los blogs de estos ciberdiarios les permiten tener voz en internet, tanto si sólo quieren ordenar sus pensamientos o contar a sus amigos sus últimas vacaciones, como si quieren influir con su opinión en la de una enorme audiencia, de una forma sencilla e interactiva.

Pero los blogs no sólo les permiten expresar sus pensamientos. También les da la posibilidad de recibir los comentarios de aquellas personas que los leen, y que les expresan su opinión de una forma interactiva, enriqueciendo sus ideas y permitiéndoles profundizar en ellas.

De esta manera, los cibermedios han optado por incrementar la transparencia de la estructura periodística mediante blogs que hacen posible un trabajo compartido, en algunos casos, entre periodistas profesionales y usuarios, fórmula mixta de periodismo profesional y periodismo participativo. 


\section{La gran apuesta de los ciberdiarios españoles}

Cada vez son más los diarios digitales que, sabedores del interés que el público tiene en los blogs, emplean este recurso como vía para ganarse la atención de los lectores. Un reciente estudio del profesor Santiago Tejedor (2010 a) establece que los blogs poseen una presencia muy amplia en los cibermedios iberoamericanos, donde cerca de un $82 \%$ posee bitácoras.

Según el propio Tejedor, en sus inicios, los blogs servían para comentar, cuestionar, supervisar o hacer un estricto seguimiento de lo publicado en los cibermedios. Sin embargo, los medios en línea pronto descubrieron el potencial que, desde el punto de vista estratégico, poseen estos instrumentos.

Las primeras experiencias en España datan de principios de 2003, cuando lavozdegalicia.es puso en marcha un blog en donde el periodista David Beriain comenzó a publicar en forma de diario sus impresiones de la contienda bélica en Irak desde el mismo lugar de los hechos, además de contestar a las preguntas que le planteaban los internautas ${ }^{2}$.

Sin embargo, la gran apuesta de los cibermedios españoles por los blogs no llegaría hasta 2005, cuando ya muchos medios extranjeros habían adoptado el formato como una parte de su oferta. La utilización de los blogs se veía como una táctica más para aumentar el atractivo de los medios y ediciones digitales.

En enero de 2005, la edición digital del diario gratuito Qué! apostaba directamente por el Periodismo 3.0, la socialización de la información. Los propios lectores del gratuito creaban el contenido de la web del diario a través de los blogs. Y los contenidos más interesantes se acababan publicando en la edición de papel. Por primera vez se reconocía a los lectores como productores de contenidos dentro de este tipo de prensa, siguiendo la estela de Slashdot, Barrapunto, Indymedia, etc.

Poco a poco, los grandes medios comenzaron a comprender que el proceso parecía imparable y que debían satisfacer a sus audiencias haciéndolas partícipes de sus contenidos. De esa manera, entre otras ventajas, se podía atender a temas y acontecimientos fuera de la agenda común de los medios.

Para contrarrestar la aparición de Qué!, otro gratuito, 20minutos apostó también por la apertura del diario a los lectores ${ }^{3}$. Y unas semanas más tarde aparecieron los blogs en el diario dirigido por Arsenio Escolar, quien, a su vez, se convertía en el primer director de un medio que utilizaba los blogs para dialogar directamente con los lectores, para contarles, entre otras cosas, algunas interioridades del diario gratuito ${ }^{4}$.

\footnotetext{
${ }^{2}<$ http://www.lavozdegalicia.es/especiales/guerra_irak/index_diario.jsp>

${ }^{3}<$ http://www.20minutos.es/zona20/>

${ }^{4}<$ http://blogs.20minutos.es/arsenioescolar/post/2005/09/05/me-da-poco-vertigo>
} 
Los gratuitos fueron los primeros en dar a conocer los blogs a la opinión pública, si bien, unos meses antes, ya existían otros dos blogs profesionales en la Red. El primero lo escribió José Cervera para elmundo.es, en cuya sección El Navegante apareció el blog Retiario en 2004 para finalizar su periplo dieciocho meses después 5 . Y ya en enero de 2005, Javier Pérez de Albéniz, también en elmundo.es comenzaba su crítica a la televisión en El Descodificador ${ }^{6}$. La oferta de blogs de este ciberdiario en la portada se incrementó en febrero de ese mismo año con dos nuevos: El Escorpión ${ }^{7}$, de Alejandro Gándara, y Política blog ${ }^{8}$, de Victoria Prego.

Elmundo.es pronto se convirtió en el medio digital con más blogs, si bien, algunos de ellos nunca han desarrollado todos los elementos conversacionales ni hipertextuales o multimedia presentes en otros blogs ${ }^{9}$. Por el contrario, ha experimentado con todos los formatos: blogs de opinión, para coberturas singulares, especializados, etc.

Pronto, otros ciberdiarios optaron también por contratar blogueros ya expertos y otros convirtieron a sus propios periodistas en blogueros. ABC, La Razón o El País comenzaron a ofrecer los primeros blogs desde 2005, año que algunos autores consideran de referencia (Larrondo, 2005; Guallar, 2009).

En marzo de 2005, apareció La Tejedora, primera experiencia de elpais.com con los blogs y cuyo rediseño trajo consigo su desaparición. Poco a poco, Prisacom fue generalizando su uso, empleándolos para cubrir acontecimientos informativos concretos y como medio especializado. Tal y como se reconocía desde el propio diario, la 'filosofía' que envolvía esta importante transformación, se nutría principalmente no sólo de los aspectos formales que caracterizan a la blogosfera, sino muy especialmente del concepto de 'periodismo ciudadano' o 'periodismo 3.0', nacido, criado y ensolerado precisamente en el entorno blogger.

También en 2005, los ciberdiarios Abc.es, Diariovasco.com ${ }^{10}$, Elcorreo.com, Laverdad.es, Ideal.es, Hoy.es, Sur.es y Larioja.com fueron los primeros medios del grupo Vocento en ofrecer blogs en sus sitios de Internet. Periodistas y colaboradores monopolizaban la autoría de aquella primera oferta de bitácoras destacadas, que ascendía a un total de treinta. Tres años después, el número de títulos se habría de multiplicar exponencialmente, consiguiendo una mayor visibilidad integrándose en las portadas de estos ciberdiarios y codeándose con las noticias más relevantes de la jornada. En marzo de 2008, un primer censo de bitácoras de

\footnotetext{
${ }^{5}<$ http://navegante2.elmundo.es/navegante/weblog.html>

${ }^{6}<$ http://www.elmundo.es/elmundo/hemeroteca/blogs/descodificador/2005/01.html>

${ }^{7}<$ http://www.elmundo.es/elmundo/hemeroteca/blogs/escorpion/2005/08.html>

${ }^{8}<$ http://www.elmundo.es/elmundo/hemeroteca/blogs/prego/2005/10.html>

${ }^{9}$ Algunos de los blogs de elmundo.es nunca han pasado del formato de columna.

${ }^{10}$ En enero de 2005, Diariovasco.com fue pionero en el empleo de blogs bajo el sistema de software libre B2Evolution dentro del grupo Vocento.
} 
autores destacados del Grupo Vocento, cifraba en 176 títulos distribuidos entre las trece cabeceras que poseen una versión impresa de pago ${ }^{11}:$ Abc, El Correo, El Diario Vasco, El Diario Montañés, La Verdad, Ideal, Hoy, Sur, La Rioja, El Norte de Castilla, El Comercio, La Voz de Cádiz y Las Provincias (Palomo y Meso, 2009). Ese número prácticamente se ha duplicado en apenas tres años (Tabla 3)

Los ciberdiarios despertaron y poco a poco todos se lanzaron a incluir blogs -incluso han terminado calando en la prensa regional (Orihuela, 2004)-, con características diferentes, en sus páginas. Muchos de estos ciberdiarios se decantaron por la puesta en marcha de blogs temáticos en los que periodistas especializados en esos ámbitos tratan la información de una manera diferente a como lo hacen en el periódico. De hecho, la posibilidad de mantener un blog en un cibermedio ha sido ofrecida a los corresponsales en el extranjero, probablemente los más frustrados por no ver todos sus textos publicados (Hermida y Thurman, 2008). Lavanguarida.es, Abc.es o Elcorreo.com, entre otros, son claros ejemplos de esta apuesta por la visibilidad de los contenidos internacionales.

Y tampoco se puede olvidar que los blogs constituyen una parte de la oferta informativa del medio, concebida como diálogo para estimular la participación de los usuarios. Precisamente algunos de los diarios regionales del grupo Vocento fueron también pioneros en España al ofrecer a sus lectores la herramienta necesaria para que estos escribieran sus propios blogs personales en sus ediciones digitales, mezclándose con los de los periodistas profesionales, colaboradores y columnistas.

Paralelamente, Internet ha cambiado la forma de trabajar de los periodistas ${ }^{12}$ y ha abierto vías de participación a los ciudadanos; dos cuestiones positivas sobre las que conviene reflexionar e investigar. Y es aquí donde englobamos la presente investigación, que tiene como objeto de estudio los blogs destacados ${ }^{13}$ en los ciberdiarios del grupo Vocento, subrayando la implantación de esta herramienta con objeto de responder al deseo de estos medios por conectar con la comunidad, rompiendo con la unidireccionalidad de los mensajes periodísticos, convirtiendo a los receptores en emisores y viceversa.

\footnotetext{
${ }^{11}$ En este estudio no se incluyó el gratuito Qué! porque su funcionamiento en Internet era atípico con respecto a las versiones digitales de los diarios de pago de Vocento. Su incorporación al grupo multimedia en verano de 2007 impidió que se implantara la misma estrategia que caracterizaba al resto de los cibermedios de Vocento, y en marzo de 2008 su oferta de contenidos on line se reducía aún a textos generados por lectores. En abril de 2008 ya se podía apreciar su rediseño, y un predominio de noticias firmadas por agencias de información, aunque en su sección de blogs seguían sin destacar ninguno creado por redactores o firmas expresamente invitadas. De hecho, en mayo de 2008 no aparecía aún la versión digital del gratuito en el listado de portales locales de la web corporativa de Vocento, apartado en el que sí se recogen las ediciones digitales de $A B C$ y de las doce cabeceras regionales del grupo.

12 A mediados de la década de los noventa Don Middleberg y Steven Ross publicaron una macroencuesta a periodistas norteamericanos para medir la influencia que la Red tenía en sus rutinas profesionales. El estudio reflejó los nuevos hábitos del profesional en el entorno en línea, como el uso intensivo del correo electrónico para la elaboración de entrevistas y el envío/recepción de notas de prensa; la localización de nuevas fuentes informativas o el tiempo invertido en navegar por internet. La investigación, actualizada anualmente, ha servido de inspiración para varias tesis doctorales españolas (Palomo, 2003; Masip, 2005).

${ }^{13}$ No existe una denominación estandarizada dentro del grupo Vocento para distinguir estas aportaciones de las realizadas por la audiencia, y junto a 'blogs destacados' figura también la opción de 'bloggers del medio digital', 'blogs de autor', 'blogs firmados' y 'blogs de expertos'.
} 


\section{Objetivos, ámbito y metodología}

Como bien se viene diciendo, una de las fórmulas de participación más extendida entre los cibermedios es la de los blogs, herramienta por excelencia del ciberdiario 2.0 (Tejedor, 2010 b). La inmensa mayoría incorpora blogs, ya sean propios, ya sean de lectores a los que ceden tales espacios. Dejando de lado sus ventajas como formato fácil de usar e integrar en los portales de los cibermedios y aunque en este segundo caso posibilitan a los usuarios convertirse en autores, se trata de una fórmula mixta de periodismo profesional y periodismo participativo en función del 'grado de apertura' a la participación que tengan otros usuarios sobre los mismos. Esto es, si están abiertos a comentarios y a la filosofía de la blogosfera o se trata tan sólo de un uso institucionalizado del formato, con distinta finalidad, al tratarse, la de los blogs, de una fórmula considerada como «el arma perfecta para recuperar la confianza de la audiencia al fijar una relación simbiótica» (Meso y Palomo, 2008).

El objetivo del presente artículo es determinar las características que presentan los blogs de autor ${ }^{14}$ de los ciberdiarios del grupo Vocento, por tratarse de uno de los principales grupos de comunicación multimedia del territorio español, especializado en prensa gracias a sus 14 cabeceras de referencia (Tabla 1), con un elevado tráfico según organismos oficiales ${ }^{15}$, por alojar la más amplia oferta de blogs de autores destacados y por ser pionero en impulsar el fenómeno blog entre sus usuarios.

Ante los cambios en los hábitos de consumo de la información con la aparición de nuevos soportes y la demanda de los usuarios de movilidad, simultaneidad e interactividad, Vocento, apoyado en la fortaleza y reconocimiento de sus marcas, ha realizado una apuesta firme por Internet. La estrategia de Vocento en la Red se basa en tres ejes fundamentales: mejora de contenidos online con el apoyo de contenido audiovisual, el desarrollo de red nacional de clasificados, y nuevos canales de comunicación con la audiencia (Vocento, 2011).

Para el presente estudio hemos seleccionado 337 blogs pertenecientes a las trece cabeceras del grupo Vocento -los doce regionales más el de tirada nacional-, que poseen una versión impresa de pago (Tabla 2).

\footnotetext{
${ }^{14}$ La denominación varía de unos ciberdiarios a otros. Así, mientras en el ideal.es y en el diariovasco.com son "Blogs firmados", en el elcorreodigital.com reciben la nomenclatura de "Blogs de autor". Por el contrario, en lavozdigital.es son "Blogs lavozdigital.es" y en el diariosur.es, "Blogs destacados". Nosotros emplearemos la denominación que emplean en el ciberdiario vizcaíno por considerarla más acorde. Y se refieren a los blogs escritos por periodistas del medio, expertos en la materia o personas reconocidas por el público, si bien en ocasiones, algunos de estos blogs dejan de lado la consideración de sus autores, y pasan a ser más interesantes por el tema que desarrollan (Domínguez, 2009).

15 Vocento con más de 10,6 millones de usuarios únicos, ocupó en 2010 la primera posición de audiencias online en el ranking de grupos de comunicación en España y se mantiene como la séptima compañía en la clasificación de las principales empresas de internet, según Nielsen NetView (Vocento, 2011). Los buenos resultados de Vocento en Internet se deben, principalmente, al liderazgo de sus portales de información y noticias. Los doce portales regionales de Vocento mantuvieron en diciembre de ese año el liderazgo en sus respectivos ámbitos de influencia, gracias a la cobertura de noticias y eventos locales. En el último año, los portales que más crecieron fueron laverdad.es $(+60,1 \%)$, sur.es $(+54,5 \%)$, lasprovincias.es $(+29,4 \%)$, elcorreo.com $(+14,5 \%)$, elcomerciodigital.com $(+12,7 \%)$ y nortecastilla.es $(+11,3 \%)$. Abc.es, por su parte, tuvo un crecimiento del $30,6 \%$ en $2010 .<$ http://www.vocento.com/actualidad-vocentolider-internet-2010-20110118.php>.
} 
Tabla 1. Cabeceras de referencia del grupo Vocento

\begin{tabular}{|c|c|c|c|c|}
\hline \multicolumn{5}{|c|}{ MEDIOS IMPRESOS } \\
\hline \multicolumn{2}{|c|}{ Prensa Regional } & $\begin{array}{c}\text { Prensa } \\
\text { Nacional }\end{array}$ & $\begin{array}{c}\text { Prensa } \\
\text { Gratuita }\end{array}$ & $\begin{array}{l}\text { Suplementos y } \\
\text { Revistas }\end{array}$ \\
\hline $\begin{array}{c}\text { El Correo } \\
\text { El Diario Vasco } \\
\text { El Diario } \\
\text { Montañés } \\
\text { La Verdad } \\
\text { Ideal } \\
\text { Hoy }\end{array}$ & $\begin{array}{c}\text { Sur } \\
\text { La Rioja } \\
\text { El Norte de Castilla } \\
\text { El Comercio } \\
\text { Las Provincias } \\
\text { La Voz de Cádiz }\end{array}$ & $A B C$ & Qué! & $\begin{array}{c}\text { XL Semanal } \\
\text { Mujer Hoy } \\
\text { Hoy Corazón } \\
\text { Pantalla Semanal } \\
\text { Inversión y } \\
\text { Finanzas }\end{array}$ \\
\hline
\end{tabular}

Fuente: Vocento. Elaboración propia

Tabla 2. Distribución de blogs de autor en los ciberdiarios del grupo Vocento ${ }^{16}$

\begin{tabular}{|c|c|}
\hline Ciberdiario & Número de blogs de autor \\
\hline Elcorreo.com & 51 \\
\hline Abc.es & 53 \\
\hline Nortecastilla.es & 30 \\
\hline Elcomerciodigital.com & 43 \\
\hline Diariosur.es & 31 \\
\hline Lavozdigital.es & 5 \\
\hline Hoy.es & 7 \\
\hline Larioja.com & 19 \\
\hline Diariovasco.com & 25 \\
\hline Ideal.es & 10 \\
\hline Lasprovincias.es & 6 \\
\hline Eldiariomontanes.es & 24 \\
\hline Laverdad.es & 33 \\
\hline TOTAL & $\mathbf{3 3 7}$ \\
\hline
\end{tabular}

Fuente: Elaboración propia

${ }_{16}$ Sólo se han tenido en cuenta aquellos blogs que se adecuan a la definición dada de "blog de autor". No se ha contabilizado un blog del Diariovasco.com que también se oferta en Elcorreo.com. 
A pesar de que ya ha pasado más de una década desde que apareciera el primer blog ${ }^{17}$, no son muchas las investigaciones sobre la importancia y repercusiones de este modelo en la prensa en línea española. La investigación presente está encaminada a cubrir parte de ese hueco. En este sentido, este trabajo esté orientado a definir los principales rasgos de este nuevo modelo dentro de los ciberdiarios del grupo Vocento; observar y analizar sus cualidades, definir sus pautas.

Este estudio se ha ordenado en dos grandes apartados. En el primero de ellos se pasa revista a los aspectos conceptuales y teóricos sobre lo que entendemos por participación activa de la audiencia de un cibermedio. Hemos definido los rasgos de este modelo de conversión de un sujeto pasivo en uno activo en el proceso de producción informativa, sus orígenes, sus rasgos más característicos, sus posibilidades, sus diferentes modalidades, con especial incidencia en los blogs de autor, en los que nos detenemos más tiempo: los contenidos informativos más habituales, sus rasgos formales, la actualización y los modelos de complicidad que se produce entre autor y usuario, entre otros aspectos.

De hecho, el segundo apartado está dedicado íntegramente a estos blogs albergados en los cibermedios y elaborados por periodistas del propio cibermedio o personal cualificado que los emplean para mantener un contacto con su audiencia. Obviamente, lo que presentamos en esta comunicación es una parte de ese proyecto mucho más ambicioso y a su vez centrado en aspectos mucho más concretos de estos blogs, entre los que se encontrarían la formación de los autores de los mismos, los motivos que impulsaron su creación, la implicación de éstos con otros modelos de participación activa de las audiencias, etc. En definitiva, en esta comunicación se perfilan las características formales y más elementales de lo que ofrecen los blogs de los ciberdiarios del grupo Vocento, cuyas versiones en papel son las más leídas en sus respectivas zonas de influencia y una de ellas, El Correo, es además el diario propiamente regional más vendido del Estado.

A la hora de afrontar el apartado metodológico de nuestro trabajo hemos tenido en cuenta las propuestas de la profesora Palomo (2006).

Para el estudio, se han contabilizado durante los dos primeros meses de 2011 el número total de blogs de autor que se alojaban en los cibermedios elegidos. Una primera conclusión que obtenemos de esta primea observación es el impulso dado desde el grupo Vocento a los blogs de autor, si nos atenemos a la variación sustancial en el número de los mismos. Como se puede observar en la Tabla 3 , en 2005 el número de blogs de autor albergados en los ciberdiarios del grupo Vocento era de 30 . Y seis años después, ese número se ha multiplicado por diez.

Tabla 3. Blogs de autor en los ciberdiarios del grupo Vocento

\begin{tabular}{|c|c|c|c|}
\hline AÑO & $\mathbf{2 0 0 5}$ & $\mathbf{2 0 0 8}$ & $\mathbf{2 0 1 1}$ \\
\hline N $^{\text {a }}$ BLOGS & 30 & 176 & 337 \\
\hline
\end{tabular}

Fuente: Elaboración propia

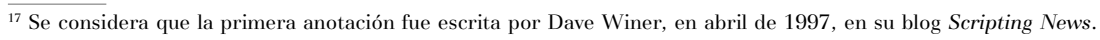


Durante un periodo de dos semanas, se han aplicado en cada uno de los blogs una serie de variables para esta comunicación; desde la autoría hasta la temática, el número de comentarios, la actualización de los contenidos, la existencia de enlaces y tags, etc. entre otros ítems.

\section{Resultados de la investigación}

\subsection{El motivo de la creación}

Existen numerosas definiciones de lo que es un blog, reflejo de las peculiaridades que motivaron su creación y que diferencian a unos de otros. Ensayar una nueva definición nos llevaría a redundar en las numerosas descripciones que se han realizado durante los últimos años, cada una de las cuales destaca, fundamentalmente, la relevancia de la participación.

Junto al prestigio que da la marca del cibermedio que alberga los blogs, éstos aparecen con el firme propósito de conformar un espacio virtual en el que aparentemente se produce una contribución personal -y, en ocasiones, colectiva- de variopintos contenidos: gustos, aficiones, autopromoción, conocimientos, denuncias, etc.

En lo que también parecen coincidir muchos de estos blogs, es, precisamente, en el motivo que origina o impulsa su creación. Así, son muchos los que reconocen que la creación y mantenimiento de estos espacios no parten únicamente de las organizaciones empresariales. El abanico de opciones está representado también por el elenco de responsables de los mismos que encuentra en los blogs un vehículo de expresividad e interconexión rápido.

Así, los hay que pretenden fomentar la participación y los comentarios de los usuarios invitándoles a contar lo que éstos quieran, a mostrar sus opiniones, quejas. Los hay también que justifican su creación en función de unos intereses concretos; o incluso quienes buscan dar información que, quizás de otra manera, no tendría cabida en el medio convencional impreso.

Así las cosas, a la rapidez con la que puede difundirse la información, se añaden otras ventajas que explicarían la creación de estos blogs por periodistas o personas invitadas por el medio: el diálogo constante con la audiencia -idea repetida hasta la saciedad y sobre la que insistiremos nuevamente- o la reivindicación de un periodismo independiente. Es una actividad más comprometida con el ciudadano, en la que el periodista abandona la figura del intermediario para introducir sus comentarios con un estilo más íntimo, espontáneo y libre que el periodístico (Palomo, 2006).

\subsection{Fecha de la creación}

A lo largo de estos últimos años, los ciberdiarios del grupo Vocento han redefinido su función en Internet incorporando en el año 2007 la sección denominada «Participación», donde la audiencia se transforma en el principal 
emisor. Mientras los medios de otros grupos limitan la intervención del lector, se puede observar que los ciberdiarios de Vocento han incorporado herramientas que han incrementado el protagonismo del usuario en la configuración de sus contenidos. Y en este sentido, se puede observar (Tabla 4) como si bien ya en 2005 -y en algún caso, con anterioridad-, algunos de estos ciberdiarios comenzaban a albergar blogs elaborados por periodistas del propio cibermedio o invitados, que los emplean para mantener un contacto con su audiencia, ha sido en los últimos dos años cuando más se ha notado el incremento en el número de blogs.

Tabla 4. Año de creación de los blogs en los ciberdiarios de Vocento

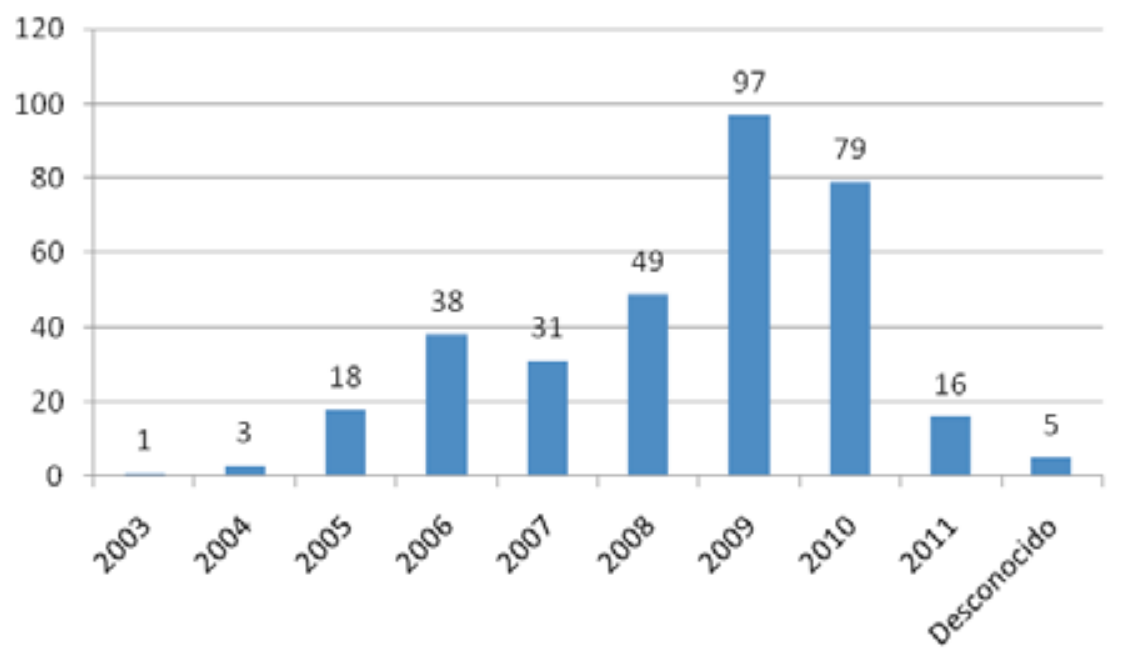

Fuente: Elaboración propia

\subsection{La autoría}

En el análisis de los blogs de los ciberdiarios del grupo Vocento se constata la existencia de bitácoras tanto individuales como mantenidas por diversos autores que comparten intereses comunes. Es decir, existen tanto blogs en los que una sola persona se convierte en editor y productor de sus propias inquietudes y/o saberes, como blogs en los que destaca la colaboración de más de un autor, cada uno de los cuales asume el papel de informador y nutren con sus contenidos los mismos. En un porcentaje pequeño de los blogs analizados ha resultado imposible determinar la autoría de los mismos 
Tabla 5. Autoría de los blogs (según no autores)

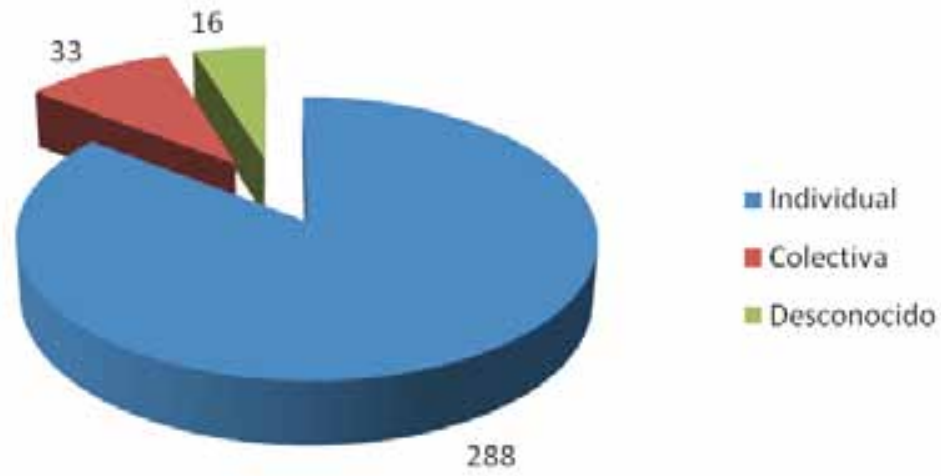

Fuente: Elaboración propia

Analizando la autoría de estos blogs, se observa también un desequilibrio entre la presencia masculina y la femenina. Existe un número de blogs (49) en los que no se puede detallar si están escritos por un hombre o una mujer, bien por tratarse de un blog colectivo (que bien pudiera ser una sección del medio, una asociación) o bien porque no se puede concretar la autoría.

Tabla 5. Autoría de los blogs (por sexos)

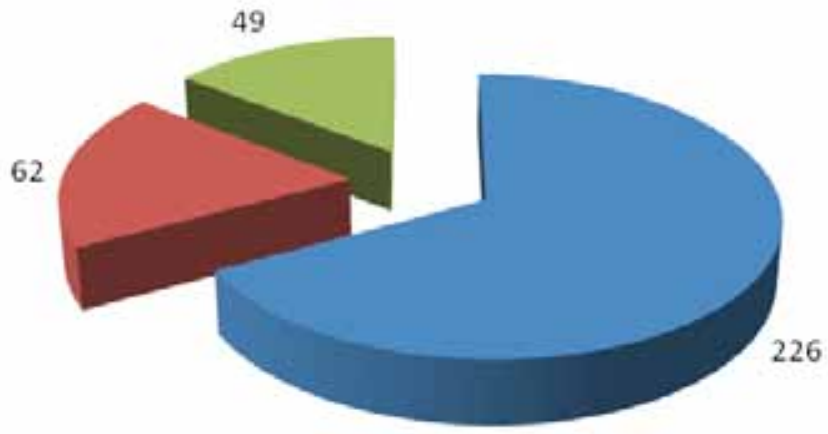

- Hombres

Mujeres

Desconocids

Fuente: Elaboración propia 


\subsection{La temática}

Los blogs de autor en los ciberdiarios analizados se muestran como manifestaciones que posibilitan escribir y opinar sobre una gran diversidad de asuntos. Constituyen puntos de encuentro con otras personas que comparten sus mismos intereses, iniciativas que dejan entrever una cierta necesidad de mantener un espíritu de comunidad. Abarcan cualquier posibilidad temática, cualquier clase de objetivo y utilidad y, en algunos casos, adscritos a una organización; a una tarea; o colectivo específico.

Las modalidades de categorización son muy amplias, prácticamente tanto como el número de los que hemos analizado. El abanico de modelos reproduce las opciones más diversas, reflejo del dinamismo de la sociedad actual: nuevas tecnologías, ocio y cultura, deportes, fotografía, empresa y economía, gastronomía, música, tauromaquia, etc.

Tabla 6. Número de blogs por temática

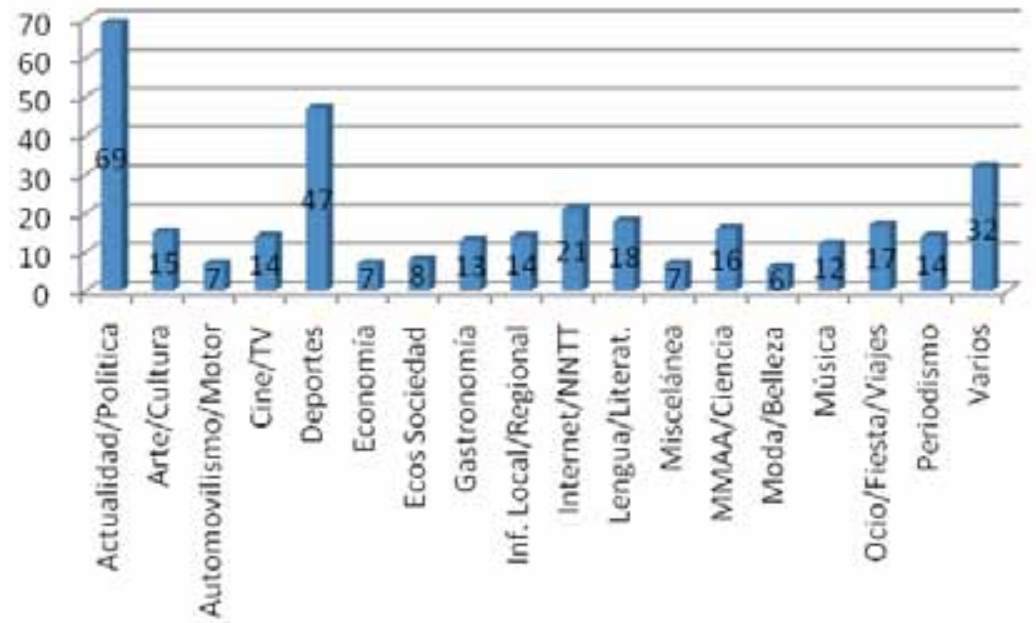

Fuente: Elaboración propia

Prácticamente la totalidad de los blogs están centrados en una materia, siendo la información de actualidad y la política el eje central con 69 blogs de la oferta total. El deporte (47) e internet y las nuevas tecnologías (21) encabezan un ranking en el que se evitan los contenidos controvertidos. Se trata, en resumidas cuentas, de poner en práctica un periodismo más sosegado y de ofrecer unos contenidos que, al contrario de lo que puede ocurrir en una redacción, sí interesan directamente al autor. 


\subsection{Actualización de los contenidos}

Los blogs se caracterizan, en general, por su gran facilidad de creación y mantenimiento, lo que la hace accesible a cualquier usuario. Su esencia se centra en la frecuencia de la puesta al día de los mensajes, en su actualización, un valor intrínseco a los blogs. Resulta evidente que si un blog se pone en marcha y casi nunca o nunca se actualiza, pierde gran parte de su interés (Carrillo y Castillo, 2009).

Algunos nacen con vocación de permanencia, mientras otros se especializan en cubrir un acontecimiento concreto y dejan de actualizarse cuando el hecho noticioso concluye. De los blogs analizados, sólo el 71,2\% de los creadores de los mismos se toman la molestia de actualizar sus contenidos, frente al 21,1\% que no lo hacen; algunos porque han cesado ya en su actividad; otros porque su autor se encuentra inmerso en otra actividad periodística que le hace imposible mantener activo el blog; otros porque cesó el motivo por el cual fueron creados; y otros, porque su creador no saca el tiempo suficiente para 'alimentarlo' ${ }^{18}$. Un $7,7 \%$ presentan una actualización irregular, en el sentido de que determinados meses tienen una superabundancia de contenidos y en otros apenas si escriben algún texto.

Tabla 7. Actualización de los blogs de Vocento

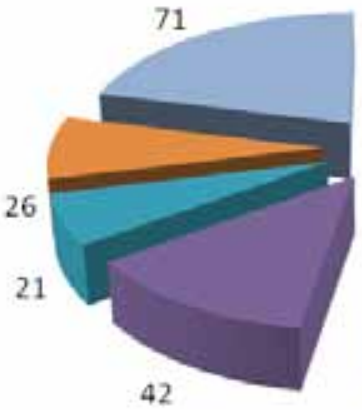

42

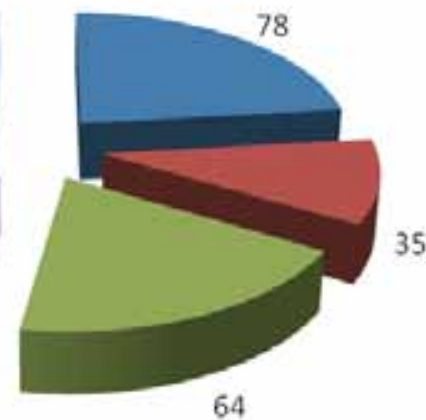

64
$1 / 3$ semana

= $4 / 5$ semana

$1 / 3$ mes

$4 / 5$ mes

Diariamente

Irregular

No actualizado

Fuente: Elaboración propia ${ }_{18}^{18}$ Para la presente investigación, se ha considerado que un blog no está activo si al menos en los dos últimos meses no
ha introducido ningún contenido nuevo en el mismo. 


\subsection{El diseño}

Según se desprende del análisis de los blogs, normalmente éstos no destacan por su diseño. Por norma general, los blogs son textuales, si bien algunos enriquecen sus contenidos con imágenes y, cada vez más, con sonido y vídeo.

En la concepción de cualquier blog tiene mucha importancia los enlaces tanto a contenidos ya publicados con anterioridad como a otros sitios u otros blogs, lo que, además de facilitar el acercamiento a otras fuentes, ponen de manifiesto, nuevamente, la constitución de comunidades interconectadas, abiertas. Sin embargo, del estudio se concluye que sólo el $46 \%$ incluye enlaces en los post (Tabla 8 ), a pesar de que el hipertexto es la esencia que determina la transparencia del blog. El $71,2 \%$ acompaña sus textos con imágenes (Tabla 9) y un $34,1 \%$ incluye contenidos multimedia (Tabla 10), fundamentalmente, vídeo, ya que sólo seis blogs, del total de los analizados $(1,8 \%)$ incluyen documentos de audio.

\section{Tabla 8. Presencia de enlaces en los post de los blogs de Vocento}
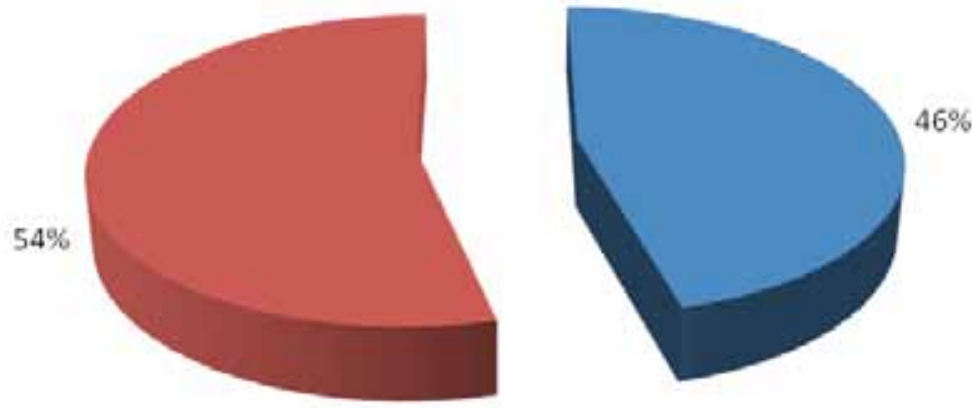

Fuente: Elaboración propia 
Tabla 9. Presencia de imágenes en los post de los blogs de Vocento

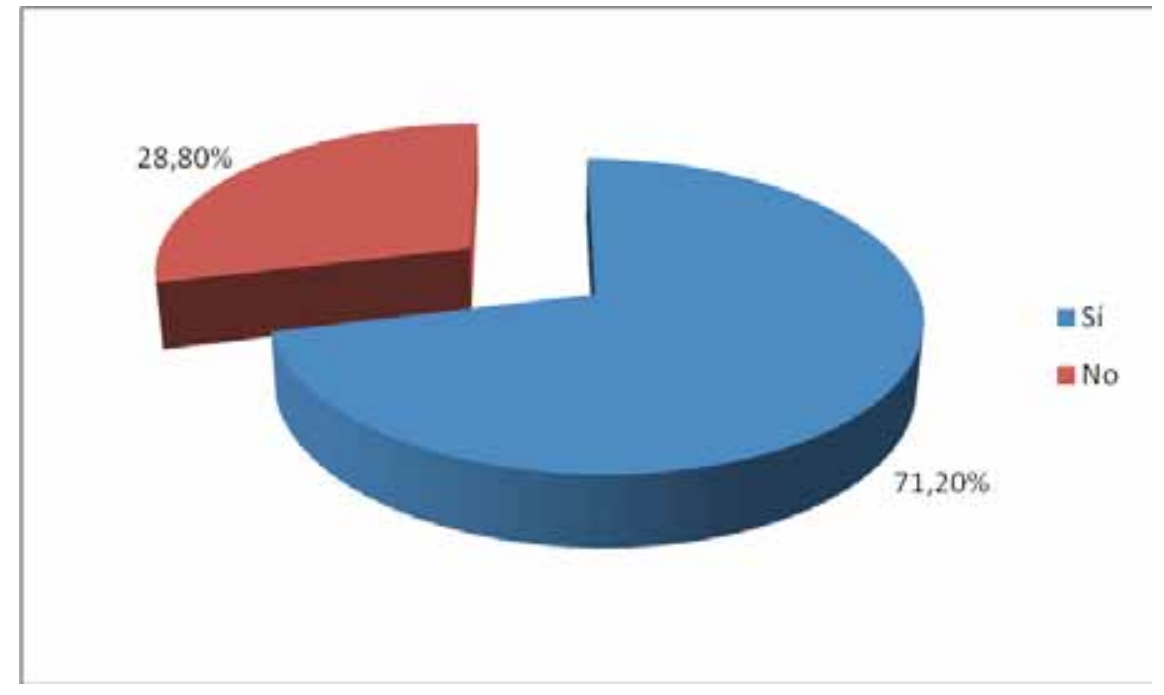

Fuente: Elaboración propia

Tabla 10. Presencia de contenidos multimedia en los post de los blogs de Vocento

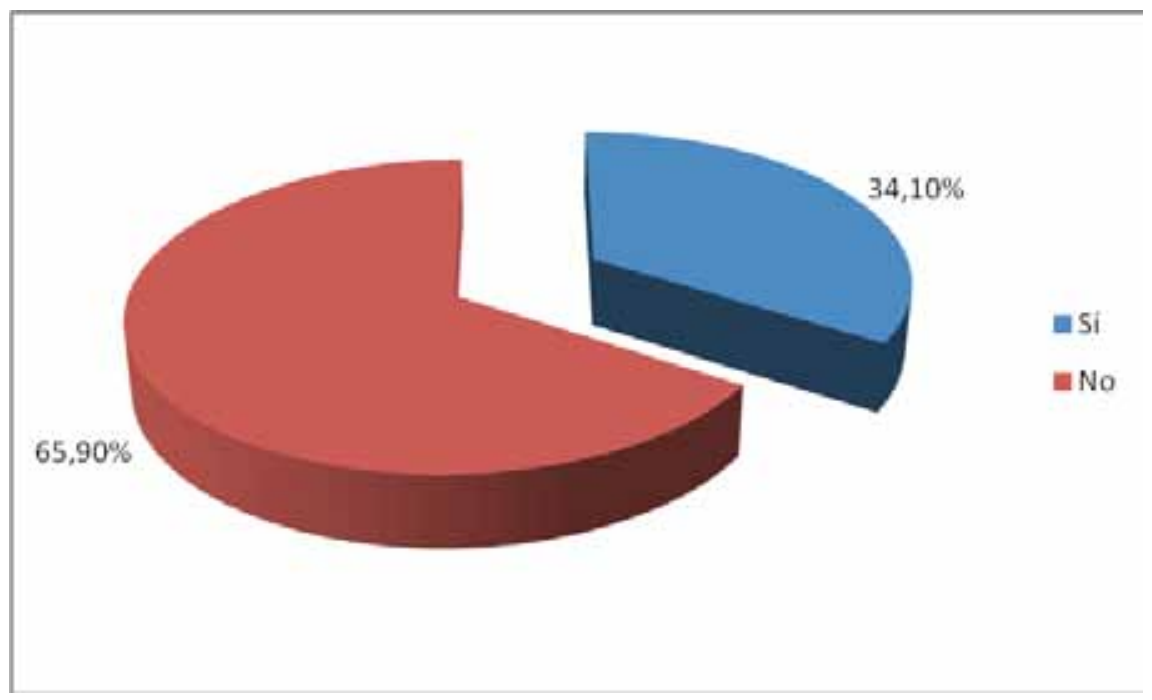

Fuente: Elaboración propia 


\subsection{Grados de intervención}

El desarrollo de las vías de participación de los usuarios en estos blogs de autor mostró, desde el primer momento, que hay varios grados de intervención que pueden aplicarse según los objetivos que persiguen los promotores del medio digital y los deseos de éstos. El blog favorece, de esa manera, una relación de complicidad entre el autor y los lectores. Así, muchos periodistas descubrieron que difundir su correo electrónico en sus blogs no era una buena idea si lo que se pretendía era dar una respuesta a los usuarios que demandaban una mayor intervención en los procesos comunicativos, poniendo comentarios a los post. Muchos responsables son reticentes a abrir esa vía -de hecho, sólo 43 blogs del total analizado facilitan el correo electrónico de su autor-.

Lo cierto es que se han popularizado mucho más otros modelos que, con sus imperfecciones -no siempre funciona o no siempre contestan los responsables- ofrecen resultados muy positivos y confianza y posibilidades para el futuro. Nos referimos a la sección «Contacto» -presente en un 46,9\% de los blogs analizados- a través de la cual se solicitan la colaboración de los usuarios en el establecimiento de propuestas de temas concretos a tratar, y que consigue crear una comunidad activa, que se gestiona adecuadamente bajo la supervisión del responsable del blog.

Una característica del blogging es la permanente relación con los otros, mediante comentarios e hiperenlaces entre blogs. El comentario es uno de los grandes elementos conversacionales, ya que permite que cualquier lector pueda dejar su opinión o aportar otras ideas. No todos los blogs admiten comentarios, y algunos sólo permiten los comentarios a un grupo de usuarios restringido, pero la mayoría tiene abierta esa posibilidad. Muchos blogueros consideran que un blog sin comentarios no es un blog.

\section{Tabla 11. Comentarios en los blogs de autor de Vocento}

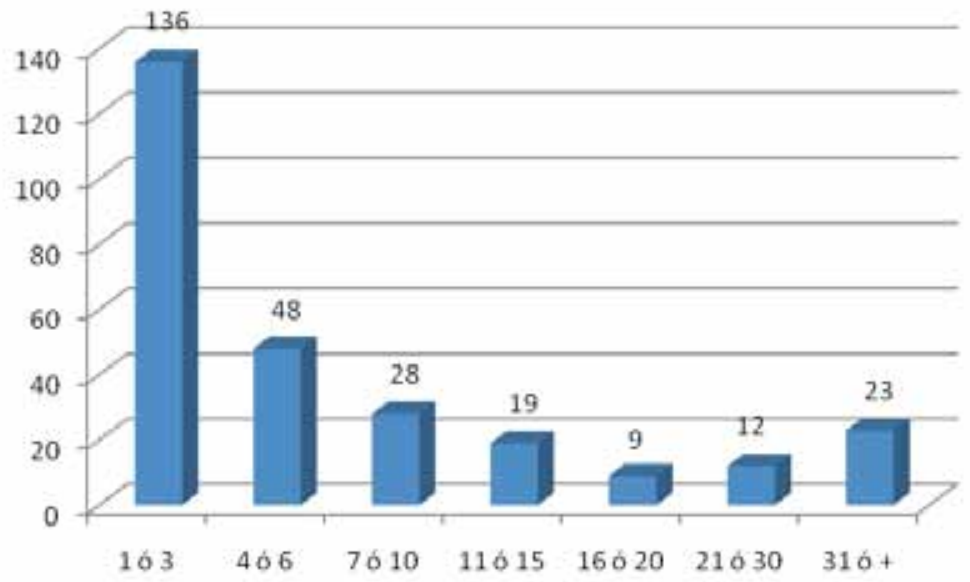

Fuente: Elaboración propia 
Sólo 62 blogs $(18,4 \%)$, del total analizados no presentan comentarios de los usuarios en los post. El resto, en mayor o menor medida, sí que tienen comentarios en los que participan las audiencias (Tabla 11). Tal y como se observa, 136 de los blogs analizados presentan entre 1 y 3 comentarios, mientras que poco más de una veintena tienen por encima de los 31 comentarios.

Estos blogs de autor están abiertos a la participación de los usuarios para introducir sus comentarios. De esta forma, lo que comienza siendo un espacio personal acaba convirtiéndose también en un espacio colectivo, esto es, el lugar de interacción de un grupo de personas bien a partir de lo expuesto por un autor o autores, bien por el trabajo colaborativo de todos ellos (Pou Amérigo, 2009).

Pero también existe relación entre el autor del blog y sus lectores por otras vías. En este sentido, durante los últimos años se ha observado que las relaciones construidas a través de blogs, se han visto ampliadas con otras plataformas. De hecho, es común que los bloggers busquen estar conectados por otras vías, como las redes sociales. Twitter (67 blogs) y Facebook (28) son las más empleadas, si bien no son las únicas: Tuenti (10), MySpace (4), Flickr (2) y Linkedin (1) también son utilizadas, en ocasiones de manera aislada y en otras, combinadas. Se aprecia que distintos tipos de redes se superponen para dar lugar a redes más complejas (Flores Márquez, 2010).

Tabla 12. Uso de redes sociales en los blogs de Vocento

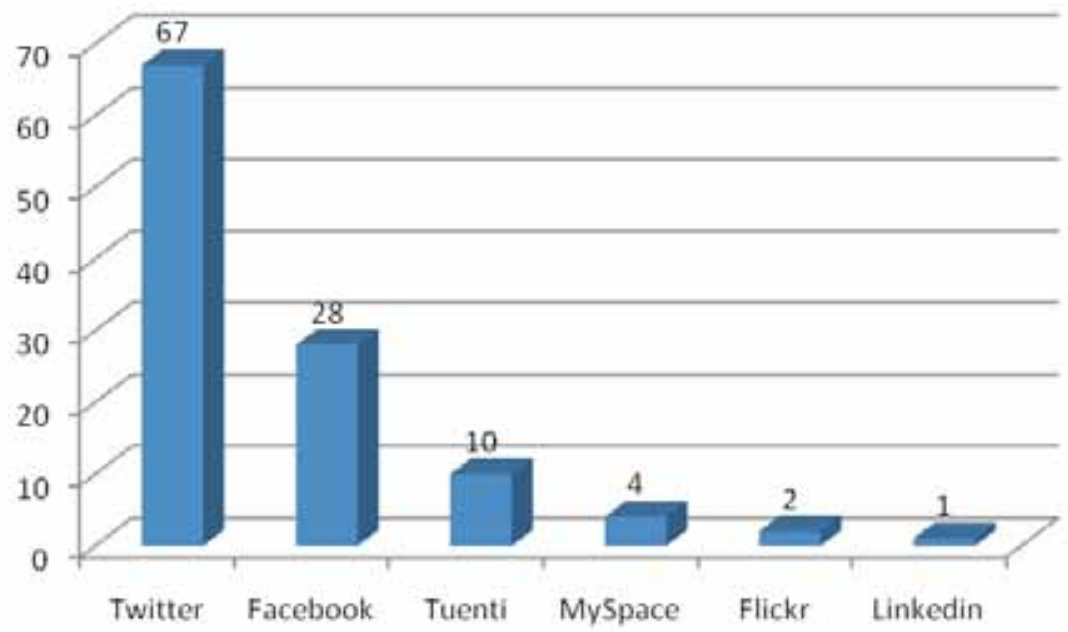

Fuente: Elaboración propia 


\subsection{Otros}

Los blogs además de las funcionalidades que hemos definido hasta ahora y que son elemento diferenciador de su particular arquitectura, incorporan otras características más avanzadas y que completan su utilidad y proyección. Un buen ejemplo de esto último es la presencia de buscador de contenidos -todos los blogs analizados disponen de él- por palabras o incluso por frases; la generación de RSS para la sindicación de contenidos, el tratamiento y agregación de RSS; o la gestión de comentarios.

La sindicación de contenidos constituye una auténtica revolución que ha venido a modificar la manera en que se consume la información (Fumero, 2005), ya que posibilita la distribución de titulares y una descripción de los últimos contenidos actualizados a través de internet de manera automática y en tiempo real a un usuario que previamente se ha tenido que suscribir. El posterior acceso a los datos se obtiene mediante los lectores o agregadores, herramientas específicas que posibilitan la recuperación de la información sindicada.

El total de los blogs analizados dispone de este proceso de sindicación de contenidos, lo que repercute en la rapidez de buscar y recuperar documentos de interés, evitando la pérdida de tiempo y esfuerzo que se invierte en la búsqueda de las aportaciones más recientes.

Por otro lado, merece la pena destacar la dependencia de los blogs del medio que los alberga, lo que se nota en la URL de éstos. Sólo 20 blogs del total disponen de una dirección propia.

\section{Conclusiones}

Los ciberdiarios del grupo Vocento comienzan a impulsar los blogs como sección específica a partir del año 2005, siendo, en la actualidad, el acceso directo, con pestaña propia entre las secciones.

Abc.es y Elcorreo.com son los diarios digitales que prestan mayor atención a los blogs de autor, como lo atestigua el hecho de que sean los dos cibermedios que mayor número de blogs ofertan. Por el contrario, en el lado opuesto de la balanza se situarían Lavoz.es, Lasprovincias.es y Hoy.es.

Como norma general, se observa la existencia de un blog elaborado de manera individual, por un hombre, que facilita su perfil -no siempre completado del todo- con una actualización periódica de 1/3 contenidos a la semana, que acompaña sus textos con imágenes y que utiliza el recurso de un formulario para ponerse en contacto con sus audiencias, además de brindar la posibilidad de que éstas realicen comentarios a los post.

Se constata que las temáticas que se abordan responden a las convencionales, con cinco grandes materias: Actualidad/Política, Deportes, Internet/Nuevas 
Tecnologías, Lengua/Literatura y Arte/Cultura. Ahora bien, es evidente la existencia de otras temáticas de gran vigencia y que 'arrastran' a audiencias por su interés: Información regional/local, Economía, Cine/Televisión, Gastronomía, Moda/Belleza. Y también otras materias más 'residuales' (Juegos de mesa, Misterios, Huertas...), más difíciles de clasificar.

\section{Referencias}

Beckett, Charlie (2010). El rescate del periodismo. En: Infoamérica, $n^{0} 2$. Málaga: Universidad de Málaga, 45-57.

Carrillo Durán, $M^{a}$.V.; Castillo Díaz, A. (2009). Los blogs en la prensa regional online. La 'actualidad' y la 'actualización' en un nuevo soporte. En: Global Media Journal México, Vol. 6, $\mathrm{n}^{0}$ 12. Monterrey (México): Tecnológico de Monterrey, 20-36. Disponible en <http://redalyc.uaemex.mx/src/inicio/ArtPdfRed. jsp?iCve $=68712864002>$ [Consulta, el 3/03/2011].

Domínguez Quintas, Susana (2009). El periodismo ciudadano y el valor de la participación. En: Pérez, P.; Rivas, P.; Gelado, R. (coords.). Periodismo ciudadano: posibilidades y riesgos para el discurso informativo. Salamanca: Publicaciones Universidad Pontificia de Salamanca.

Flores Márquez, Dorismilda (2010). Estar con los otros: presencias, proximidades y sentidos de vínculo en las redes de bloggers. En: Mediaciones Sociales, $\mathrm{n}^{\mathrm{o}}$ 6, I semestre. Madrid: Universidad Complutense de Madrid, 145-161.

Fumero, Antonio (2005). El abecé del universo blog. Un tutorial sobre blogs. En: Telos, $n^{0}$ 65, octubre-diciembre. Madrid: Fundación Telefónica, 46-59.

García de Torres, Elvira; Pou Amérigo, Ma José (2003). Características de la comunicación digital. En: Salaverría, Ramón; Díaz Noci, Javier (coords.). Manual de Redacción Ciberperiodística. Barcelona: Ariel.

Guallar, Javier (2009). Blogs en publicaciones periodísticas y científicas en España: dos situaciones divergentes. El caso del blog de EPI. En: Anuario ThinkEPI, Vol. 3. Barcelona: Taylor\&Francis, 75-87.

Hermida, A.; Thurman, N. (2008). A clash of cultures. The integration of usergenerated content within professional journalistic frameworks at British newspaper websites. En: Journalism Practice, $\mathrm{n}^{0}$ 2(3). Oxford: Routledge, 343-356.

Larrondo, Ainara (2005). Presencia del formato weblog en los cibermedios: una aproximación a sus usos y funciones. En: Revista Latina de Comunicación Social, $\mathrm{n}^{\circ}$ 60, Tenerife (Canarias): Universidad de La Laguna. En <http://www. ull.es/publicaciones/latina/200539larrondo.htm> [Consulta, el 3/03/2011].

Lasica, J.D. (2003). Let journalists blogs. En: Cyberjournalist.net. En <http:// www.cyberjournalist.net/news/000361.php> [Consulta, el 3/03/2011]. 
López, Xosé (2008). La participación en los diarios digitales: similitudes y diferencias entre los cibermedios europeos y brasileños. En: VI Encontro Nacional de Pesquisadores em Jornalismo. Universidade Metodista de Sào Paulo. Noviembre.

López, X. Otero, M. (2007). Bitácoras. La Coruña: Netbiblo.

Masip, Pere (2005). Presència i ús d'internet a les redaccions. Periodistes, rutines professionals i tecnologia. Tesis Doctoral. Universitat Ramon Llull.

Meso, Koldo; Palomo, Bella (2008). Los blogs de autor en los ciberdiarios de referencia españoles. En: Prisma.com, $\mathrm{n}^{0}$ 7. Oporto (Portugal): Universidade do Porto. En <http://prisma.cetac.up.pt/223_Los_blogs_de_autor_en_los_ciberdarios_de_referencia_espanoles_Koldo_Meso_e_Bella_Palomo.pdf> [Consulta, el 3/03/2011].

Ortiz de Zárate, Alberto (2008). Manual de uso del blog en la empresa. Barcelona: Edicions Cantalaia.

Orihuela, J.L. (2004). Los weblogs: de la revolución a la consolidación. En: Chasqui, $\mathrm{n}^{0}$ 85. Quito (Ecuador): CIESPAL. En <http://www.comunica.org/ chasqui/85/orihuela85.htm>. [Consulta, el 3/03/2011].

Orihuela, José Luis (2006). La revolución de los blogs. Madrid: La esfera de los libros.

Palomo, Bella (2006). Periodistas en la red. En: Informe Anual de la Profesión Periodística 2006, 309-319.

Palomo, Bella (2003). El uso redaccional de Internet en la prensa diaria española. Tesis Doctoral. Universidad de Málaga.

Palomo, Bella; Meso, Koldo (2009). Perfil y comportamiento de los autores de los blogs destacados en los ciberdiarios de Vocento. En: Anàlisi, $n^{0} 38$, Barcelona: Universidad Autónoma de Barcelona, 99-116.

Pisani, F.; Piotet, D. (2009). La alquimia de las multitudes. Cómo la web está cambiando el mundo. Barcelona: Paidós.

Pou Amérigo, Ma José (2009). Periodismo de opinión y comunidades virtuales: los blogs como espacios de interactividad entre periodistas y lectores. En: En Pérez, P.; Rivas, P.; Gelado, R. (coords.). Periodismo ciudadano: posibilidades y riesgos para el discurso informativo. Salamanca: Publicaciones Universidad Pontificia de Salamanca.

Ruiz, C. et al (2009). Audiencias participativas: los problemas de un espejismo. Actitudes de los medios de proximidad catalanes. En: Comunicación presentada en el I Congreso Internacional de Ciberperiodismo y Web 2.0. Bilbao. Noviembre.

Smith, Anthony (2010). El periódico que viene. En: Infoamérica, $n^{0} 2$. Málaga: Universidad de Málaga, 7-19. 
Tapscoot, D.; Williams, A. (2007). Wikinomics. La nueva economía de las multitudes inteligentes. Barcelona: Paidós Empresa.

Tejedor, Santiago (2010a). La Web 2.0: Herramienta de marketing y posicionamiento de los cibermedios iberoamericanos. En: Cuadernos de Información, $\mathrm{n}^{\circ}$ 27. Santiago (Chile): Universidad Católica de Chile, 15-24.

Tejedor, Santiago (2010b). Los cibermedios iberoamericanos en la Web 2.0. Transformaciones y tendencias de los medios online de América Latina, España y Portugal en el contexto de la web social. En: Mediaciones Sociales, $\mathrm{n}^{0}$ 7, II semestre. Madrid: Universidad Complutense de Madrid, 57-87.

Vocento (2011). Vocento, S.A. y Sociedades Dependientes. Informe de resultados 2010. En < http://www.vocento.com/pdf/info_periodica/2011/resultadosenero-diciembre.pdf> [Consulta, el 24/06/2011].

\section{Referencia de este artículo}

Meso Ayerdi, Koldobika (2011). Presencia y contenidos de los blogs en los ciberdiarios del grupo Vocento. En: adComunica. Revista Científica de Estrategias, Tendencias e Innovación en Comunicación, $\mathrm{n}^{0}$ 2. Castellón: Asociación para el Desarrollo de la Comunicación adComunica, Universidad Complutense de Madrid y Universitat Jaume I, 159-181. 